\title{
Laser machined macro and micro structures on glass for enhanced light trapping in solar cells
}

\author{
David Moore · Mahfujur Rahman · Denis P. Dowling · Patrick J. McNally · Dermot Brabazon
}

\begin{abstract}
In order to increase the efficiency of solar cell modules it is necessary to make the optimum use of light incident upon them. Much research has been done on improving light absorption through front surface texturisation and light trapping schemes. Laser light is commonly used in industry for various applications including marking and texturisation. By controlling laser parameters, it is possible to tailor macro and micro structures in most materials. The $\mathrm{CO}_{2}$ laser used in this investigation emits radiation at $10.6 \mu \mathrm{m}$ with the ability to pulse in the microsecond range. The laser was used to ablate grooved textures in the fused quartz material, used in this study as the light trapping medium, following which an analysis of the effects of the laser parameters on the texture geometry and surface morphology was performed through a combination of cross sectioning and scanning electron microscopy. Transmission through the textured glass was improved for most samples after acid etching. The light trapping effects of the best performing textures were analysed by investigating the effects on a silicon solar cell's performance at varying angles of incidence. Results indicated a significant increase in light trapping when light was incident at acute angles. For an angle of incidence of $10^{\circ}$ a relative increase in efficiency of up to $51 \%$ was observed.
\end{abstract}

\section{Introduction}

In order to reduce the cost per watt of solar cells it is necessary to either reduce the cost of manufacturing, or increase the efficiencies of the cells themselves. While higher cell efficiencies generally require increased semiconductor quality and improved fabrication techniques, developments in light management within the cells have led to advancements in cell output for both wafer-based and thin-film solar cells [1-3]. Optical losses in solar cells can occur by reflection from the surface, transmission through the cell, and from reflection from any front surface contacts, and can cause losses as high as $40 \%$ to $50 \%$ [4]. Therefore, solar cells are normally textured at the surface to reduce reflection. Pyramidal texturing of crystalline silicon (c-Si) using chemical etching is a popular process. This enables the surface to trap light better through enhancement of beneficial secondary reflections and scattering [47]. Other research has focused on geometrical light trapping through improved cell and substrate morphologies. In thin-film solar cells for instance, textured transparent conducting oxide (TCO) layers are a popular way to achieve improved light trapping performance [810]. Another proposed method of trapping light in solar cells is to texture the front cover glass of a solar module. Simulations in the literature indicate significant benefits of textured surfaces and superstrates in solar modules with particular emphasis being placed on the increase in short-circuit currents, which are attributed to an increase in the number of times a 
ray will pass through a cell due to total internal reflection $[2,11]$. Other ray-tracing simulations indicate that texturing increases light trapping at acute angles of incidence [12].

The light scattering effects have been found to improve the efficiency of thin-film solar cells in particular due to the increased optical path lengths which improve absorption for normally poorly absorbed wavelengths [1, 13-15]. This research proposed the use of a $\mathrm{CO}_{2}$ laser to manufacture effective micro-grooves in the front surface of the superstrate cover glass to enhance the light trapping ability in the active layers behind. By controlling the laser parameters carefully it is theoretically possible to control the morphological parameters of the textured glass on the micro- and nanoscales. In this paper the effects of processing parameters on the textures created and the effects of those textures on the efficiency of solar cells with sunlight at varying angles of incidence are presented.

\section{Experimental}

Fused quartz glass was chosen as the superstrate material for this study as it not only has excellent transmission characteristics across the AM1.5G spectrum, but also good thermal shock resistance making it more suitable for micro-second pulse laser machining. Fused quartz plate of $2 \mathrm{~mm}$ thickness (MultiLab Ltd.) was diced into $10 \times 10 \mathrm{~mm}$ squares for use as superstrates. The texturisation of the glass was carried out using a Rofin DC015 $\mathrm{CO}_{2}$ slab laser operating at $10.6 \mu \mathrm{m}$ wavelength. Duty cycle $(\%)$, pulse repetition frequency $(\mathrm{Hz})$, and traverse speed $(\mathrm{mm} / \mathrm{s})$ were the main parameters considered in the investigation. After initial screening experiments were completed, the maximum and minimum values of each parameter were fixed and a $3^{3}$ general factorial design of experiments (DOE) was completed with the value indicated in Table 1 [16]. The textures were created by raster scanning the laser beam over the glass sample to produce a texture of parallel grooves measuring eight by eight millimetres. Each perturbation of the laser parameters used resulted in different channel dimensions, and an average of the channel width was used to determine a line spacing of 200 $\mu \mathrm{m}$ which was used in the raster scan.

Following the laser processing the parasitic absorption loss in the glass due to the surface structure was measured by using a $100 \mathrm{~mm}$ integrating sphere set-up (LabSphere, model 4PGPS-040-SF) with spectrometer (Ocean Optics USB 2000).

Table 1 Laser texturing parameters used in this investigation

\begin{tabular}{llll}
\hline $\mathrm{CO}_{2}(10.6 \mu \mathrm{m})$ & laser processing parameters & & \\
Level & 1 & 2 & 3 \\
\hline Power $(\mathrm{W})$ & 7.5 & 15 & 22.5 \\
Duty cycle $(\%)$ & 2 & 4 & 6 \\
Pulse frequency $(\mathrm{Hz})$ & 160 & 280 & 400 \\
Traverse speed $(\mathrm{mm} / \mathrm{s})$ & 1.67 & 5 & 8.33 \\
\hline
\end{tabular}


The textured glass sample was held inside the sphere with the incoming light incident at $8^{\circ}$ to the surface normal. This allowed all reflected and transmitted light to be considered in the measurement.

A separate set of samples with the same processing parameters were etched in $40 \%$ hydrofluoric acid (Sigma Aldrich, 01010) in order to improve the surface morphology and to reduce the parasitic absorption loss in the textured glass. The samples were immersed in HF for two periods of 10 minutes. After each etching step the samples were rinsed for three periods of 5 minutes in deionised water with gentle agitation by stirring.

Commercially available silicon solar cells (Evergreen Solar, String RibbonTM wafers) were diced into eight by eight millimetres sections using a $355 \mathrm{~nm}$ pulsed nanosecond laser (Blueacre Technology). The front and rear contacts were soldered to the cells, and they were then encapsulated in an elastic transparent resin (ACC Silicones, QSil 216) and allowed to set at room temperature for 24 hours ( see Fig. 1).

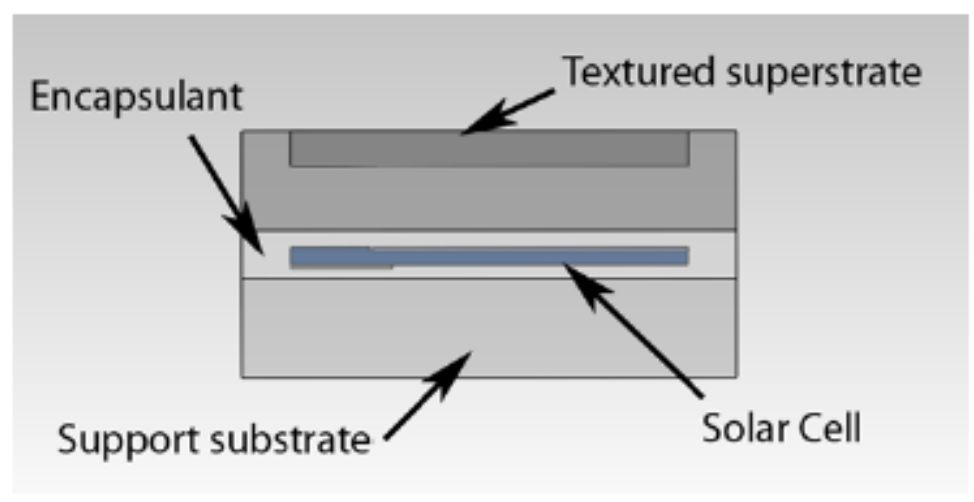

Fig. 1 Cross section of configuration of solar cell encapsulation

Texture dimensions were measured by cross sectioning the channels and imaging the cross sections using scanning electron microscopy (Zeiss EVO LS15). The surface morphology of the laser textures were observed via scanning electron microscopy before and after HF etching to qualitatively assess the effect of the etching. The two textured samples with the lowest parasitic absorption losses(samples 20 and 21) were used in the subsequent I-V measurement, as it was understood that they would provide the best chance of performance improvements in the solar cell. Laser processing parameters for these samples are shown in Table 2.

The set-up for I-V curve measurement of the solar cell is shown in Fig. 2. This was measured for samples 20,21 , and an untextured reference as superstrates at varying angles of incidence between a normal incidence angle $\left(90^{\circ}\right)$ and an incidence angle of $10^{\circ}$ in increments of $10^{\circ}$. 
Table 2 Laser texturing parameters-Samples 20 and 21

\begin{tabular}{lll}
\hline Parameter & Sample 20 & Sample 21 \\
\hline Duty cycle (\%) & 2 & 2 \\
Pulse freq $(\mathrm{Hz})$ & 280 & 400 \\
Speed $(\mathrm{mm} / \mathrm{s})$ & 8.33 & 8.33 \\
\hline
\end{tabular}

Fig. 2 Setup of cell efficiency measurement with textured superstrates

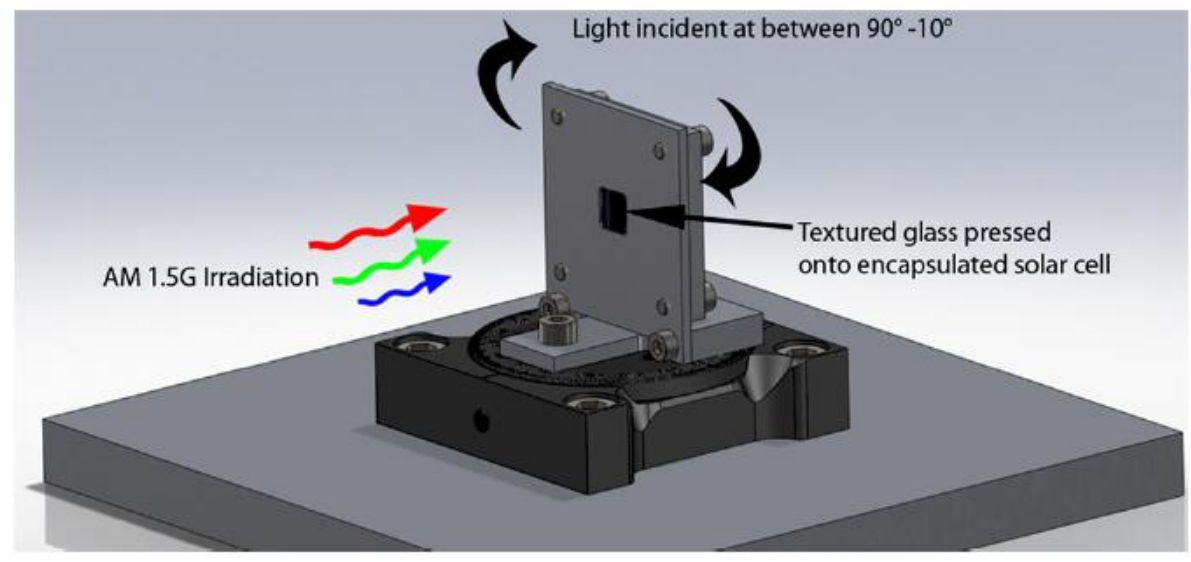

The textured glass superstrate and the encapsulated solar cell were held in contact using this device, where securing screws allowed for the application of sufficient pressure in order to eliminate air gaps at the glass/encapsulant interface. The photovoltaic measurements (I-V characteristic) of the solar cell in conjunction with different textured superstrates were carried out using a Newport Oriel solar simulator. The solar simulator was equipped with a $450 \mathrm{~W}$ Xe lamp filtered to global AM1.5G spectral conditions and an illumination area of $78 \mathrm{~cm}^{2}$ [17]. The light intensity was adjusted by using a NREL-calibrated reference silicon cell. The data were recorded using an automated data acquisition system (Gamry PCL4 300 series) under $870 \mathrm{~W} / \mathrm{m}^{2}$ solar simulated irradiance and an externally applied bias potential. The backside of the cell was carefully shielded to avoid any influence of stray light.

\section{Results and discussion}

Figures 3(a) and (b) show the cross sections of the maximum and minimum texture depths achieved by laser processing. Some cracking due to thermal shock is visible at the bottom of the groove in Fig. 3(a). The size of the textures varied from 72-974 $\mu \mathrm{m}$ in depth, and 146$213 \mu \mathrm{m}$ in width at the widest point. The parasitic absorption loss under the AM1.5G spectrum was measured to be between $2.27 \%$ and $63.28 \%$. This was largely attributed to the rough surface morphology remaining after laser processing. Through process mapping it was found that laser power and traverse speed were the most influential process parameters affecting the parasitic absorption loss in the material. From qualitative visual analysis of SEM data it was apparent that the surface roughness increased at higher laser powers. 
Fig. 3 Cross sectional view of the groove texture. (a) Sample 16 with the maximum (duty cycle $6 \%$, PRF $160 \mathrm{~Hz}$, speed

$5 \mathrm{~mm} / \mathrm{s}$ ) and (b) Sample 21 with the minimum texture depths achieved by laser ablation
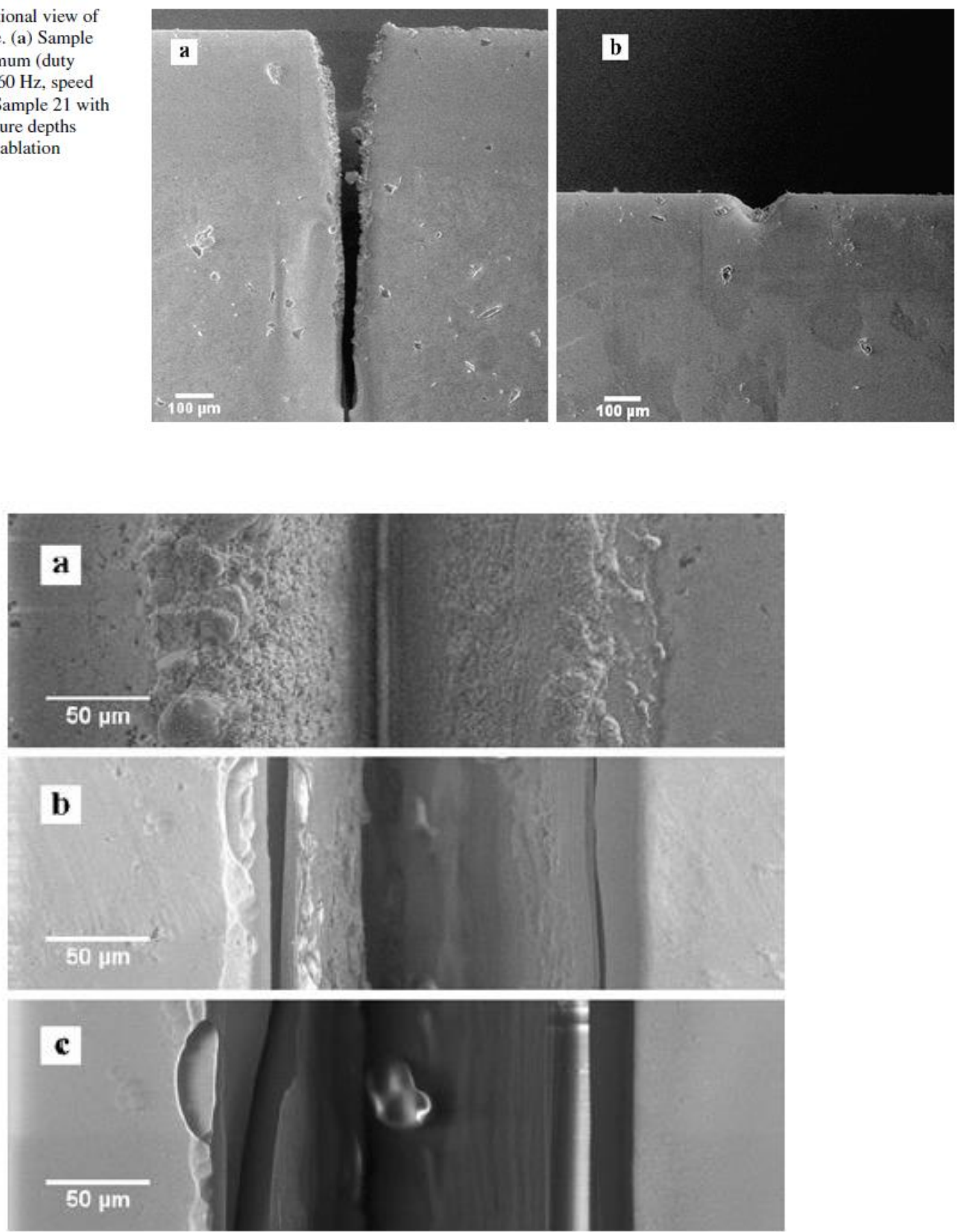

Fig. 4 Top down view of ablated grooves showing surface morphology (duty cycle $4 \%$, PRF $400 \mathrm{~Hz}$, speed $1.67 \mathrm{~mm} / \mathrm{s}$ ). Before HF etching (a), after etching for 10 minutes (b) and after etching for 20 minutes $(\mathbf{c})$

This can be attributed to the ablation-vaporisation mechanism utilised in creating the microgrooves and the increased material removal rates at higher powers in conjunction with the resolidification of material on the surface from cooling vapour as shown in Fig. 4(a). 
In order to improve the surface morphology, acid etching was performed. By acid etching with hydrofluoric acid for periods of 10 minutes it was possible to observe the smoothing effect of the rough surface morphology as shown in Fig. 4 [18, 19]. As the increase in parasitic absorption is attributed to increased laser power and vapour deposition during processing, surface material removal by HF treatment provided the highest gains to the textures created using the higher powers. While most samples displayed improved transmission characteristics after etching, for the two samples (samples 20 and 21) with the lowest parasitic absorption losses, the effects of acid etching on transmission were negligible $(<0.50 \%)$.

Figure 5 displays the acquired $\mathrm{I}-\mathrm{V}$ data for the same solar cell mounted under the three different superstrates; one untextured as a reference and the other two with the maximum transmission textures (samples 20 and 21).

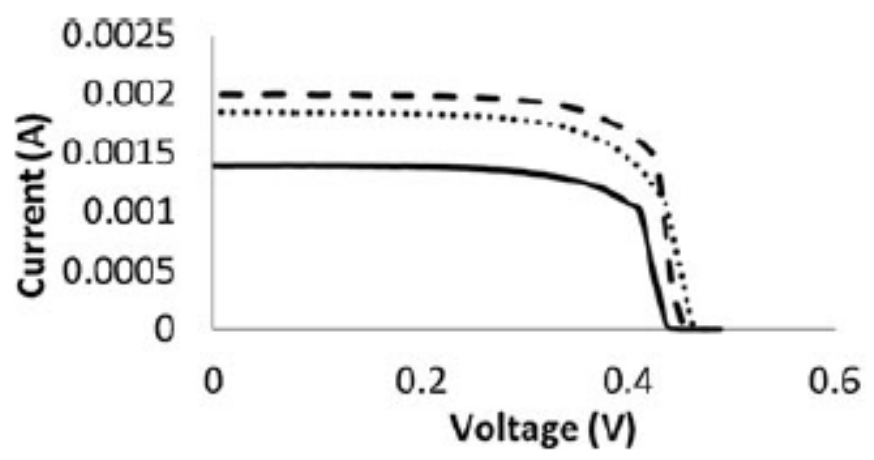

Fig. 5 I-V curves for solar cell at the acute angle of $10^{\circ}$ incidence; untextured reference (solid), sample 20 (dotted), and sample 21 (dashed)

Table 3 Parameters and results for I-V measurement with light incident at $10^{\circ}$ to surface

\begin{tabular}{llll}
\hline Sample & Untextured & Sample 20 & Sample 21 \\
\hline Depth $(\mu \mathrm{m})$ & - & 95 & 72 \\
Width $(\mu \mathrm{m})$ & - & 173 & 146 \\
$V_{\text {oc }}(\mathrm{V})$ & 0.478 & 0.483 & 0.488 \\
$I_{\text {sc }}(\mathrm{A})$ & 0.00139 & 0.00185 & 0.00201 \\
Fill factor $(\%)$ & 67.20 & 67.15 & 69.01 \\
Efficiency $(\%)$ & 0.49 & 0.66 & 0.74 \\
\hline
\end{tabular}

These data were acquired with the light incident at $10 \circ$ to the surface. The texture characteristics and $\mathrm{I}-\mathrm{V}$ data are presented in Table 3. The results indicate that at acute angles of incidence there is a significant improvement in the cell performance due to the enhanced 
light trapping effect caused by the textures on the superstrate. At $10^{\circ}$ incidence to the surface plane a relative efficiency gain in the solar cell of $51 \%$ was found for sample 21 in comparison to the untextured reference. Voc, Isc, and fill factor were also improved relatively by $2.1 \%, 44.6 \%$, and $2.7 \%$, respectively.

While there were significant efficiency gains at an angle of incidence of $10^{\circ}$, the solar cell efficiency was degraded relative to the untextured reference at more obtuse angles of incidence. Figure 6 indicates that cell efficiency was only improved relative to the untextured reference for acute angles in the range of $20^{\circ}$ to $10^{\circ}$. As shown in Fig. 3(b) the surface of the samples tested have a sinusoidal shaped cross section. According to simulations performed by SanchesIllescas et al., the highest benefit of the textured surface can be found at acute angles of incidence, which corresponds well with our findings [12]. The reduced performance at other angles could be attributed to the effect of laser processing on the surface quality itself, changes in surface composition, and also the increased path lengths travelled by the light due to enhanced scattering.

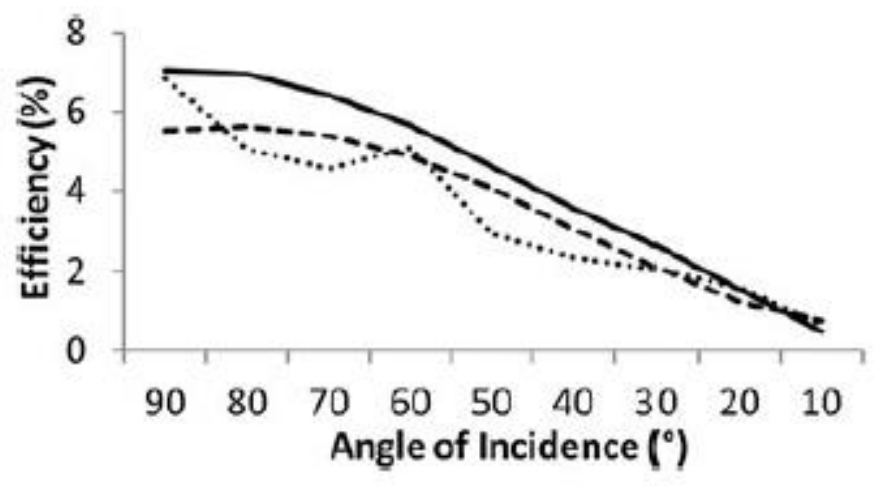

Fig. 6 Solar cell efficiency with different angles of incidence for the untextured reference (solid), sample 20 (dotted), and sample 21 (dashed)

\section{Conclusion}

Laser textures were created on fused silica glass using a $\mathrm{CO}_{2}$ laser operating in pulsed mode, for which the parameters were defined by Design of Experiments. The size of the textures varied from 72-974 $\mu \mathrm{m}$ in depth, and 146-213 $\mu \mathrm{m}$ in width. The parasitic absorption loss of light in the laser textured glass was measured using an integrating sphere and spectrometer set-up, and losses ranged from $2.25 \%$ to $44.74 \%$. The surface morphology was smoothed by HF etching for up to 20 minutes and resulted in improved transmission for most samples. The gains in transmission through acid etching of the two samples with the lowest parasitic absorption losses (samples 20 and 21) were negligible. The I-V data for the solar cell under different textures were assessed by encapsulating the solar cell in transparent resin and placing it in contact with the flat side of the laser textured front cover glass. This allowed the authors to test the characteristics of the solar cell under the textured superstrate by measuring the I-V data at varying angles of incidence. While increased performance was not found at all angles of incidence, for acute angles of incidence $\left(10^{\circ}\right)$ the relative efficiency increased by up 
to $51 \%$ with an increase in the $\mathrm{V}_{\mathrm{oc}}$ of $2.1 \%$ and in the $\mathrm{I}_{\mathrm{sc}}$ of $44.6 \%$. An improvement in the fill factor of $2.7 \%$ was also observed.

\section{References}

1. A. Luque, S. Hegedus, Handbook of Photovoltaic Science and Engineering, 2nd edn. (Wiley, Chichester, 2011), pp. 265-356

2. P. Campbell, M.A. Green, Appl. Phys. 62, 243-249 (1987)

3. D. Moore, S. Krishnamurthy, Y. Chao, Q. Wang, D. Brabazon, P.J. McNally, Phys. Status Solidi A 208, 604 (2011). doi:10.1002/ pssa.201000381

4. C.S. Solanki, in Solar Photovoltaics: Fundamentals, Technologies and Applications (PHI, New Delhi, 2009), pp. 109-114

5. P. Papet, O. Nichiporuk, A. Kaminski, Y. Rozier, J. Kraiem, J.-F. Lelievre, A. Chaumartin, A. Fave, M. Lemiti, Sol. Energy Mater. Sol. Cells 90(15), 2319-2328 (2006). doi:10.1016/ j.solmat.2006.03.005

6. D. Iencinella, E. Centurioni, R. Rizzoli, F. Zignani, Sol. Energy Mater. Sol. Cells 87(14), 725-732 (2005). doi:10.1016/j.solmat. 2004.09.020

7. K. Wijekoon, T. Weidman, S. Paak, K. MacWilliams, in 35th IEEE Photovoltaic Specialists Conference (PVSC), 20-25 June (2010). doi:10.1109/PVSC.2010.5614441

8. J.A. Anna Selvan, A.E. Delahoy, S. Guo, Y.-M. Li, Sol. Energy Mater. Sol. Cells 90(1819), 3371-3376 (2006). doi:10.1016/ j.solmat.2005.09.018

9. J. Müller, B. Rech, J. Springer, M. Vanecek, Sol. Energy 77(6) , 917-930 (2004). doi:10.1016/j.solener.2004.03.015

10. J. Müller, J. Müller, G. Schope, B. Rech, H. Schade, P. Lechner, R. Geyer, H. Stiebig, W. Reetz, in Proc. of 3rd World Conference on Photovolt. Energy Convers., vol. 2 (2003), pp. 1839-1842

11. P. Campbell, M.A. Green, Sol. Energy Mater. Sol. Cells 65(1 -4), 369-375 (2001). doi:10.1016/S0927-0248(00)00115-X 12. P.J. Sánchez-Illescas, P. Carpena, P. BernaolaGalván, M. Sidrach-de-Cardona, A.V. Coronado, J.L. Álvarez, Sol. Energy Mater. Sol. Cells 92(3), 323-331 (2008). doi:10.1016/j.solmat. 2007.09.008

13. H. Sai, M. Kondo, in 35th IEEE Photovoltaic Specialists Conference (PVSC), 20-25 June 2010 (2010). doi:10.1109/PVSC.2010. 5615886

14. X. Sheng, J. Liu, I. Kozinsky, A.M. Agarwal, J. Michel, L.C. Kimerling, in 35th IEEE Photovoltaic Specialists Conference (PVSC), 20-25 June 2010 (2010). doi:10.1109/PVSC.2010. 5617124

15. T. Yagi, Y. Uraoka, T. Fuyuki, Sol. Energy Mater. Sol. Cells 90(16), 2647-2656 (2006). doi:10.1016/j.solmat.2006.02.031

16. S.M. Karazi, A. Issa, D. Brabazon, Opt. Lasers Eng. 47(9), 956 - 964 (2009). doi:10.1016/j.optlaseng.2009.04.009

17. M. Rahman, J.M.D. MacElroy, D.P. Dowling, J. Nanosci. Nanotechnol. 11(10), 86428651 (2011). doi:10.1166/jnn.2011.3458 
18. M. Kolli, M. Hamidouche, N. Bouaouadja, G. Fantozzi, J. Eur. Ceram. Soc. 29(13), 26972704 (2009). doi:10.1016/j.jeurceramsoc. 2009.03.020

19. J. Zhao, J. Sullivan, T.D. Bennett, Appl. Surf. Sci. 225(1-4), 250 - 255 (2004). doi:10.1016/j.apsusc.2003.10.012 